\title{
Incertezas e Conflitos na relação Família/Escola em decorrência da COVID-19: um olhar a partir do Estado do Rio de Janeiro
}

\author{
Uncertainties Conflicts in Family/School relationship due to \\ COVID-19: perpectives from Rio de Janeiro
}

Carlos Alberto Lima de Almeida ${ }^{1}$

Klever Paulo Leal Filpo ${ }^{2}$

\section{RESUMO}

Este artigo propõe reflexões acerca dos conflitos surgidos nas relações entre família e escola na esteira das medidas de isolamento social decorrentes da COVID-19, especialmente a suspensão das aulas. A discussão está situada no campo do direito público por envolver o Direito à Educação e os métodos empregados para administrar ou solucionar esses conflitos. São abordadas as normativas baixadas para regulamentar as atividades educacionais durante a pandemia, o clima de insegurança jurídica subsequente, o surgimento dos conflitos e reflexões sobre a dificuldade de construir caminhos consensuais, tal como o emprego da mediação. A pesquisa é qualitativa e foi realizada a partir de fontes bibliográficas, incluindo levantamento da legislação e matérias jornalísticas pertinentes.

\section{PALAVRAS-CHAVE:}

Direito à Educação. Insegurança Jurídica. Administração de Conflitos. Mediação.

\begin{abstract}
This article proposes reflections on the conflicts that occurred in the relations between family and school in the wake of the social isolation measures resulting from COVID-19, especially the suspension of classes. The discussion is situated in the field of public law because it involves the public right to receive Education and the methods used to resolve these conflicts. Regulations issued to regulate educational activities during the pandemic, the climate of subsequent legal uncertainty, the appearance of conflicts and reflections on the difficulty of

\footnotetext{
${ }^{1}$ Pós-Doutor em Direito (UERJ). Doutor e Mestre em Política Social (UFF). Mestre em Educação (UNIVERSO). Doutorando em Educação (UFF). Professor Permanente do Programa de Pós-Graduação em Direito da Universidade Estácio de Sá. Líder do Grupo de Pesquisa Observatório das Políticas Públicas, Direito e Política Social. Advogado desde 1991. CV Lattes: http://lattes.cnpq.br/6717808991001267. E-mail: carlosalberto.limadealmeida@gmail.com.

${ }^{2}$ Doutor em Direito (UGF). Professor Permanente do Programa de Pós-Graduação em Direito da Universidade Católica de Petrópolis (PPGD/UCP). Professor do Instituto Três Rios da Universidade Federal Rural do Rio de Janeiro (ITR/UFRRJ). Pesquisador do INCT/InEAC/UFF. Advogado. Lattes: CV Lattes: http://lattes.cnpq.br/1619725989694017. E-mail: klever.filpo@yahoo.com.br.
} 
building consensual solutions. The research is qualitative and it was carried out from bibliographic sources, including survey of legislation and relevant journalistic articles.

\section{KEYWORDS:}

Right to Education. Legal Insecurity. Conflict Management. Conflicts Mediation.

\section{INTRODUÇÃO}

Neste artigo, pretendemos contribuir com reflexões propiciadas por um olhar sócio jurídico acerca dos conflitos surgidos nas relações entre família e escola, na esteira das medidas de isolamento social decorrentes da COVID-19. A discussão está situada no campo do direito público por envolver o Direito à Educação e os métodos empregados para administrar ou solucionar esses conflitos.

Essa tentativa se faz possível a partir de nossa experiência como professores de programas de Pós-Graduação stricto sensu em Direito sediados no estado do Rio de Janeiro desenvolvendo pesquisas que, partindo de diferentes olhares, tangenciam o tema da judicialização/administração de conflitos surgidos no ambiente escolar ${ }^{3}$ - e como advogados militantes, familiarizados com a atuação em demandas de consumo, isto é, envolvendo interesses dos consumidores em juízo - inclusive, por assim dizer, os consumidores dos serviços educacionais.

Como recorte temático, pretendemos explorar aqui percepções e reflexões a respeito do clima de insegurança jurídica que tomou conta do cenário educacional no Brasil - e mais especificamente no estado do Rio de Janeiro, onde estamos sediados - em função das medidas de isolamento social decorrentes da COVID-19, como explicaremos mais adiante. Neste texto, diante da necessidade de recortar nosso objeto de investigação, vamos nos concentrar nos

\footnotetext{
${ }^{3}$ A pesquisa conta com recursos do CNPq-Brasil (Chamada Universal 2016), com o Projeto "Estudo de Casos de Judicialização e Mediação de Conflitos Escolares no Município de Petrópolis, RJ", coordenador pelo Professor Klever Filpo no PPGD/UCP, sendo bolsista de iniciação científica a pesquisadora Julia Toneli Loretti Cunha.
} 
conflitos surgidos entre escolas particulares, de um lado, e os estudantes e suas famílias, de outro, na esteira daquelas medidas.

Logo, do ponto de vista jurídico, a discussão se relaciona, em primeiro lugar, à Educação, direito público subjetivo considerado um dever da família, da sociedade e do Estado, "visando ao pleno desenvolvimento da pessoa, seu preparo para o exercício da cidadania e sua qualificação para o trabalho" (CRFB, art. 205). E, sem segundo lugar, ao Direito das Obrigações e dos Contratos, envolvendo as escolas como fornecedoras dos serviços educacionais e os estudantes e suas famílias como consumidores destes mesmos serviços, quando explorados pela iniciativa privada (CRFB, art. 209). A referência às famílias faz sentido, no texto, por concentrarmos nossas atenções nas etapas da educação infantil, do ensino fundamental e do ensino médio, justificando, em geral, o envolvimento dos responsáveis pelos estudantes nessas relações jurídicas.

Interessa pensar, neste artigo, na forma como esses conflitos assim surgidos estão configurados e os meios para administrá-los, chamando atenção para uma dificuldade aparente de obter consensos para lidar com as dificuldades oriundas do combate à pandemia. Dificuldades estas que podem estar relacionadas com determinadas sensibilidades jurídicas, no sentido em que essa expressão é empregada por Kant de Lima (2011), como buscaremos explicitar mais adiante.

O ponto de partida destas reflexões, numa perspectiva histórica, é o mês de dezembro de 2019, quando a Organização Mundial da Saúde (OMS) foi alertada sobre vários casos de pneumonia na cidade de Wuhan, província de Hubei, na República Popular da China. O mundo inteiro passou a acompanhar notícias sobre um novo tipo de Coronavírus que, até então, não havia sido identificado em seres humanos. Denominado SARS-CoV-2, o vírus causa a doença COVID-19.

O ano de 2020 ainda estava em seu início quando, no mês de fevereiro, foram adotadas as medidas para adequação da legislação brasileira, visando "coordenar as ações e os serviços do SUS em todas as esferas federativas para permitir uma atuação eficiente e eficaz, mediante a definição de instrumentos que possibilitassem o enfrentamento ágil da situação de emergência 
sanitária internacional existente, objetivando a proteção da coletividade, com maior segurança jurídica"4.

A iniciativa do anteprojeto de lei submetido pelo então Ministro da Saúde foi acolhida pelo Presidente da República e resultou na Mensagem $\mathrm{n}^{\circ}$ 28, dirigida aos Membros do Congresso Nacional, por intermédio da qual, nos termos do art. 61 da Constituição da República Federativa do Brasil de 1988, submetia o projeto de lei sobre as medidas sanitárias para enfrentamento da emergência de saúde pública de importância internacional decorrente do Coronavírus.

A tramitação do Projeto de Lei nº 23/2020 ocorreu com celeridade, após aprovação do Requerimento de Urgência n ${ }^{\circ}$ 46/2020. Ele foi aprovado em sessão extraordinária realizada pela Câmara dos Deputados e remetido ao Senado Federal por intermédio do Ofício no 32/20/SGM$\mathrm{P}$, assinado pelo Presidente da referida casa legislativa ${ }^{5}$. No Senado, a tramitação foi ligeira e o texto recebido da Câmara foi aprovado sem qualquer alteração, fato noticiado por intermédio do Ofício $n^{\circ} 16 / 2020(\mathrm{SF})$, expediente que também comunicou a remessa à sanção presidencial.

Assim o ordenamento jurídico brasileiro recebeu a Lei $\mathrm{n}^{\circ} 13.979$, de 6 de fevereiro de 2020, dispondo "sobre as medidas para enfrentamento da emergência de saúde pública de importância internacional decorrente do coronavírus responsável pelo surto de 2019”. Entre elas destacam-se o isolamento, definido na lei como "separação de pessoas doentes ou contaminadas, ou de bagagens, meios de transporte, mercadorias ou encomendas postais afetadas, e outros, de maneira a evitar a contaminação ou a propagação do coronavírus"; e a quarentena, apresentada como "restrição de atividades ou separação de pessoas suspeitas de contaminação das pessoas que não estejam doentes, ou de bagagens, contêineres, animais, meios de transporte ou mercadorias suspeitos de contaminação, de maneira a evitar a possível contaminação ou a propagação do coronavírus".

\footnotetext{
${ }^{4}$ Trecho extraído da Exposição de Motivos (EM 09/2020-MS, de 03/02/2020) do Projeto de Lei destinada a dispor sobre medidas para enfrentamento da emergência de saúde pública de importância internacional decorrente do Coronavírus. Sítio eletrônico da Câmara dos Deputados, <https://www.camara.leg.br/proposicoesWeb/fichadetramitacao?idProposicao=2236343>, acesso em 13 jun. 2020.

5 A tramitação do Projeto de Lei pode ser visualizada em 〈https://www.camara.leg.br/proposicoesWeb/fichadetramitacao?idProposicao=2236343 $>$, acesso em 13 jun. 2020 .
} 
Posteriormente a lei sofreu alterações pela Medida Provisória nº 926, de 20 de março de 2020 e foi regulamentada pelos Decretos 10.282, de 20 de março de 2020, e 10.288, de 22 de março de 2020, ambos de âmbito federal. Diante da propagação do vírus em terras brasileiras, diferentes entes da federação, já no mês de março, passaram a adotar o isolamento no âmbito das respectivas competências territoriais, dentre as quais a suspensão das aulas, em escolas públicas e privadas, vinculadas ao respectivo Sistema de Ensino.

No caso do Estado do Rio de Janeiro, a suspensão das aulas deu-se em 13 de março de 2020 por meio do Decreto ${ }^{\circ} 46.970$, de iniciativa do Governador desse Estado, com prazo inicial de 15 dias, que acabaram sendo posteriormente prorrogados:

De forma excepcional, com o único objetivo de resguardar o interesse da coletividade
na prevenção do contágio e no combate da propagação do coronavírus (COVID-19),
determino a suspensão, pelo prazo de 15 (quinze) dias, das seguintes atividades:
(...)
IV - das aulas, sem prejuízo da manutenção do calendário recomendado pelo
Ministério da Educação, nas unidades da rede pública e privada de ensino, inclusive
nas unidades de ensino superior, sendo certo que o Secretário de Estado de Educação
e o Secretário de Estado de Ciência, Tecnologia e Inovação deverão expedir em 48
(quarenta e oito horas) ato infralegal para regulamentar as medidas de que tratam o
presente Decreto.

À medida em que instituições de ensino foram implementando a suspensão, muitas dúvidas, incertezas e conflitos surgiram na relação família/escola. Neste contexto é que se apresenta o problema para o qual direcionamos nossos olhares neste paper. É que, a despeito de vários textos normativos terem sido editados para regulamentar o comportamento de pessoas e instituições, a segurança jurídica que pretendiam proporcionar ainda não pôde ser alcançada até o momento, nestes tempos de pandemia, dentro do recorte aqui considerado, formando ambiente propício para o surgimento de conflitos de interesses. Por outro lado, a intensa produção legislativa acaba preenchendo um espaço que poderia ser ocupado pelas negociações entre os interessados na solução de um conflito, valorizando-se, portanto, métodos consensuais como a conciliação e a mediação - estas, por sinal, já regulamentadas no Brasil há anos ${ }^{6}$.

Pretendemos descrever o clima de insegurança jurídica que se estabeleceu, a despeito de todo o esforço normativo acima descrito, relacionando-o ao surgimento de conflitos entre as famílias e as escolas a partir do momento em que ocorreu a suspensão de aulas, na esteira da pandemia, bem como refletir sobre formas adequadas para que os mesmos possam ser

\footnotetext{
${ }^{6}$ Por exemplo, na Lei 13.140/2015, o Marco Legal da Mediação no Brasil. E a resolução 125/2010 do Conselho Nacional de Justiça.
} 
administrados. Para além disso, pretendemos desenvolver algumas reflexões a partir de propostas teóricas que buscaram explicar determinados traços característicos da cultura jurídica e sistema de administração de conflitos no Brasil, sobretudo a dificuldade de estabelecer consensos que permitam superar problemas e situações conflituosas.

\section{DISTANCIAMENTO SOCIAL, SUSPENSÃO DAS AULAS PRESENCIAIS E MÚLTIPLAS INCERTEZAS}

Na esteira do Decreto estadual no 46.970/RJ, o Conselho Estadual de Educação do Rio de Janeiro publicou a Deliberação $\mathrm{n}^{\circ}$ 376, de 23 de março de 2020, buscando orientar as instituições integrantes do Sistema Estadual de Ensino do Rio de Janeiro sobre o desenvolvimento das atividades escolares não presenciais, em caráter de excepcionalidade e temporalidade, enquanto vigentes as medidas de isolamento previstas pelas autoridades estaduais na prevenção e combate ao Coronavírus - COVID-19.

Mesquita (2020), ao abordar o tema "Mensalidades escolares e a Covid-19" relatou que, na seara da educação, creches, escolas de ensino básico e técnico, faculdades, universidades e centros universitários precisaram ser fechados em razão das determinações de isolamento. Por meio da Portaria $n^{\circ} 343$, o Ministério da Educação determinou a substituição das aulas presenciais por aulas que utilizem meios e tecnologias de informação e comunicação (acesso remoto). Em função disso - descreveu a autora - as instituições de ensino se adaptaram e passaram a utilizar plataformas digitais e outras tecnologias para continuar a prestação dos serviços educacionais.

Na visão dessa autora, o serviço continuou a ser prestado pelas escolas, ainda que não na modalidade contratada pelas partes, qual seja, a presencial. Contudo, essa adaptação provocou uma série de questionamentos e posicionamentos variados tanto das partes envolvidas na relação contratual —instituições, alunos e suas famílias — quanto de pessoas alheias a essa relação (os Procons, por exemplo). Nesse sentido, a redução das mensalidades escolares passou a ser discutida e tornou-se objeto de projetos de lei de vários estados-membros, por meio das 
Assembleias Legislativas Estaduais, e da União Federal por meio da Câmara dos Deputados e do Senado Federal.

No artigo intitulado "Análise do impacto inicial das medidas excepcionais de isolamento em decorrência do novo Coronavírus, COVID 19, na prestação do serviço de educação escolar realizado na educação básica por escolas privadas do Sistema de Ensino do Estado do Rio de Janeiro", apresentado na edição 2020 do Congresso Internacional de Altos Estudos em Direito, Almeida e Almeida (2020), descreveram o cenário de incertezas que se estabeleceu a partir da suspensão das aulas, no Brasil.

Os autores observaram que, além das dúvidas inerentes ao contexto da pandemia, passaram a ser difundidas por meio de diferentes veículos de comunicação notícias que, na visão dos autores, contribuíram para ampliar ainda mais o clima de insegurança jurídica no tocante às relações entre família e escola. Algumas notícias colacionadas por eles (ALMEIDA e ALMEIDA, 2020) foram recuperadas em suas fontes e são aqui apresentadas em formato de tabela, em ordem cronológica:

\begin{tabular}{|c|c|c|c|c|}
\hline $\begin{array}{l}\text { Veículo de } \\
\text { comunicação }\end{array}$ & $\begin{array}{l}\text { Meio de } \\
\text { Divulgação }\end{array}$ & Data & Notícia veiculada & Comentário \\
\hline PODER 360 & Digital $^{7}$ & $13 / 03 / 2020$ & $\begin{array}{l}\text { "Por covid-19, Rio de } \\
\text { Janeiro suspende } \\
\text { aulas em escolas e } \\
\text { universidades: Férias } \\
\text { antecipadas no } \\
\text { Estado" }\end{array}$ & $\begin{array}{l}\text { A antecipação de férias não está } \\
\text { contemplada expressamente no decreto }\end{array}$ \\
\hline $\begin{array}{l}\text { Agência } \\
\text { Brasil }\end{array}$ & Digital $^{8}$ & $24 / 03 / 2020$ & $\begin{array}{l}\text { "Rio de Janeiro adia } \\
\text { retorno das aulas e } \\
\text { adota ensino no } \\
\text { formato online" }\end{array}$ & $\begin{array}{l}\text { O Conselho Estadual de Educação } \\
\text { autorizou para o ensino fundamental e } \\
\text { médio a adoção do Regime Especial } \\
\text { Domiciliar com o desenvolvimento de } \\
\text { atividades escolares não presenciais, } \\
\text { não necessariamente online. }\end{array}$ \\
\hline $\begin{array}{l}\text { O Globo - } \\
\text { Rio }\end{array}$ & Digital $^{9}$ & 03/04/2020 & $\begin{array}{l}\text { "Aulas à distância } \\
\text { podem ser suspensas } \\
\text { no Rio por pedido do } \\
\text { Ministério Público" }\end{array}$ & $\begin{array}{l}2^{\text {a }} \text { Promotoria de Justiça de Tutela } \\
\text { Coletiva de Proteção à Educação da } \\
\text { Capital instaurou um procedimento } \\
\text { administrativo no dia } 19 \text { de março para } \\
\text { apurar os impactos das medidas } \\
\text { adotadas, dentre elas, a suspensão das } \\
\text { aulas, sobre a política educacional, e as } \\
\text { medidas compensatórias implantadas. }\end{array}$ \\
\hline
\end{tabular}

7 https://www.msn.com/pt-br/noticias/educacao/por-covid-19-rio-de-janeiro-suspende-aulas-em-escolas-euniversidades/ar-BB11ahM5

8 https://agenciabrasil.ebc.com.br/educacao/noticia/2020-03/rio-de-janeiro-adia-retorno-das-aulas-e-adotaensino-no-formato-online

9 https://oglobo.globo.com/rio/ministerio-publico-do-rio-recomenda-suspensao-das-aulas-distancia-no-estado-124350632 


\begin{tabular}{|c|c|c|c|c|}
\hline Veja-Rio & $\begin{array}{l}\text { Impresso e } \\
\text { Digital }^{10}\end{array}$ & $08 / 04 / 2020$ & $\begin{array}{l}\text { "Projeto para obrigar } \\
\text { instituições de ensino } \\
\text { do RJ a dar desconto } \\
\text { durante coronavírus } \\
\text { passa na CCJ" }\end{array}$ & $\begin{array}{l}\text { A notícia do projeto de lei em } \\
\text { tramitação na Assembleia Legislativa } \\
\text { do Estado do Rio de Janeiro gerou uma } \\
\text { expectativa de descontos no valor das } \\
\text { parcelas da anuidade escolar, ditas } \\
\text { mensalidades escolares, de forma } \\
\text { desvinculada dos critérios fixados na } \\
\text { legislação federal pertinente }\end{array}$ \\
\hline
\end{tabular}

O quadro evidencia as incertezas surgidas neste período, relacionadas a interpretações variadas sobre alcance e sentido das normativas que, produzidas a "toque de caixa", pretendiam orientar os envolvidos no contexto da pandemia, proporcionando segurança jurídica. Dentre essas questões, o tema mensalidades escolares passou a constituir campo para o dissenso - ou para fazer surgir a chamada espiral do conflito, nos termos empregados por Azevedo (2012). Afinal existem direitos e deveres contratualmente estabelecidos, com interpretações e argumentos defensáveis para todas as partes envolvidas, mas que nem sempre conseguem convergir de forma espontânea.

Por exemplo, a discussão surgida acerca da suposta obrigatoriedade das escolas concederem descontos, durante o período de suspensão das aulas, tornou-se rapidamente polêmica. Ela estaria amparada na teoria da imprevisão, que afirma a possibilidade de alteração das cláusulas de contratos celebradas entre particulares ou entre estes e a administração pública, a fim de ajustá-las a situações imprevisíveis supervenientes, o que seria especialmente válido por se tratar de relações de consumo - no recorte deste artigo.

Pedroso e Zeger (2020), em artigo intitulado Covid-19, "Quarentena e o contrato educacional", destacam a preocupação do impacto da pandemia nas relações jurídicas em andamento.

\footnotetext{
A adoção profilática da quarentena, inicialmente voluntária e paulatinamente imposta pela administração pública, tem causado inúmeros impactos à sociedade civil, com severas consequências econômicas a todos os segmentos da economia. Nesse momento surge uma relevante (e legítima) preocupação com as consequências que a pandemia causará nas relações jurídicas já estabelecidas, dentre as quais os contratos educacionais (PEDROSO; ZEGER, 2020).
}

Esses autores calçam sua interpretação na legislação que protege os consumidores. Defendem ser possível a aplicação do Código de Defesa do Consumidor (art. 6º V), que

\footnotetext{
${ }^{10}$ https://vejario.abril.com.br/cidade/coronavirus-ano-letivo-suspenso-rio/
} 
reconhece como direitos básicos "a modificação das cláusulas contratuais que estabeleçam prestações desproporcionais ou sua revisão em razão de fatos supervenientes que as tornem excessivamente onerosas" (PEDROSO; ZEGER, 2020), para justificar a concessão de descontos em benefício dos estudantes e suas famílias.

Com efeito, mesmo depois da publicação das normativas apontadas acima, a questão de possíveis descontos nos contratos de prestação de serviço de educação escolar permanecia em foco. Levantamento realizado por Palhares $(2020)^{11}$ revelou que "em ao menos 11 Estados, na Câmara dos Deputados e no Senado foram protocolados projetos de lei para obrigar escolas particulares e faculdades a dar desconto nas mensalidades durante o isolamento da pandemia do coronavírus". A notícia revela um dos mais polêmicos pontos de controvérsia na relação entre famílias e escolas da rede privada.

No Estado do Rio de Janeiro, a Lei 8.864 sancionada pelo Governador em 04 de junho de 2020 tornou obrigatória a concessão de descontos pelas escolas e fixou critérios para esse fim. Ficou definido que unidades cuja mensalidade fosse de até $\mathrm{R} \$ 350,00$ (trezentos e cinquenta reais) não precisariam conceder descontos. Já aquelas com mensalidade acima desse valor deveriam aplicar um desconto de $30 \%$ sobre a quantia que ultrapassasse a faixa de isenção. Entre cooperativas, associações educacionais, fundações e micro e pequenas empresas de educação, o desconto estabelecido foi de $15 \%$ para aquelas com mensalidade maior que R\$ 700,00 (setecentos reais), calculando a redução sobre a diferença entre a mensalidade e a faixa de isenção. O abatimento passou a incidir para os ensinos pré-escolar, infantil, fundamental, médio (incluindo os ensinos técnico e profissionalizante) e superior (incluindo cursos de pósgraduação).

A despeito da lei, não se obteve consenso sobre as suas vantagens ou desvantagens, tampouco ela foi capaz de afastar todas as dúvidas pertinentes. Não houve, por exemplo, definição quanto ao procedimento a ser observado para o período de suspensão das aulas que antecedeu a entrada em vigor da lei. Por outro lado, houve quem apontasse defeitos no texto, reputando-a inconstitucional por violar, dentre outros, a livre iniciativa ${ }^{12}$ e por buscar

\footnotetext{
${ }^{11}$ Disponível em < https://www.folhadelondrina.com.br/geral/onze-estados-tem-projetos-para-obrigar-descontoem-mensalidades-escolares-2986836e.html>. Acesso em 23 mai. 2020.

${ }^{12}$ Mesquita (2020) ${ }^{12}$ afirma que: [...] é possível concluir que, além de causar insegurança jurídica na relação contratual, a imposição de um percentual fixo para redução das mensalidades não observa qualquer parâmetro e
} 
uniformizar o abatimento a ser aplicado, o que não seria adequado diante das diferenças que existem entre as instituições de ensino ou quando se considera a capacidade financeira de cada família, dentre outros.

A controvérsia chegou a tal ponto que acabou dando margem a uma verdadeira batalha judicial. Ocorreu que um Mandado de Segurança coletivo foi ajuizado pelo Sindicato dos Estabelecimentos de Ensino do Rio de Janeiro (Sinepe-RJ), vindo a ser proferida nos autos uma decisão liminar que suspendeu a aplicação da lei. Contudo, poucos dias mais tarde, em 19 de junho de 2020, a liminar foi cassada por decisão do Tribunal de Justiça Estadual. Mais um capítulo dessa angustiante peça que envolveu escolas, estudantes e suas famílias em um cenário de absoluta insegurança jurídica. Posteriormente ao fechamento deste artigo, soubemos que as situações acima relatadas tiveram ainda outros desdobramentos. Mas esse relato já é suficiente para chegarmos a ponto central da discussão aqui proposta.

É interessante pensar, neste artigo, que tanto as normativas como as decisões judiciais acima referidas fizeram-se sobrepor a uma eventual possibilidade das partes envolvidas em um contrato educacional chegarem a um consenso sobre a melhor forma de lidar com os efeitos da pandemia, o que poderia ser obtido, por exemplo, por intermédio de uma mesa de negociações - instrumento contemplado na lei estadual acima referida, mas não com força suficiente para dispensar a concessão dos descontos uniformes, medida imposta por esse texto normativo, sem conferir às partes interessadas maior poder de negociação. Voltaremos a esse ponto.

\section{OUTROS CONFLITOS OBSERVADOS NO PERÍODO DE SUSPENSÃO DAS} AULAS

Entretanto, o potencial de surgimento de conflitos de interesses envolvendo famílias / escolas não se exaure no recorte financeiro que permeia a relação travada nos contratos privados. O receio quanto à qualidade da prestação dos serviços durante a pandemia; a discussão sobre o método de reposição das aulas; e até mesmo reivindicações pertinentes à

desconsidera as especificidades do caso concreto, motivo pelo qual os ajustes contratuais pelas próprias partes apresenta-se como medida mais benéfica e segura para ambos. 
manutenção da alimentação escolar ${ }^{13}$ são exemplos de dúvidas recorrentes nestes tempos de medidas de isolamento.

Para que se possa dimensionar o tamanho do problema existente no campo educacional brasileiro durante a vigência das medidas de isolamento, um instrumento a ser considerado é a Consulta Pública sobre o Parecer que trata da Reorganização dos Calendários Escolares e a realização de atividades pedagógicas não presenciais durante o período de Pandemia da COVID-19 ${ }^{14}$ promovida pelo Conselho Nacional de Educação, conforme o edital de chamamento datado de 17 de abril de 2020.

Do texto referência apresentado na Consulta Pública, intitulado "Proposta de parecer sobre a reorganização dos calendários escolares e realização de atividades pedagógicas não presenciais durante o período de pandemia da COVID-19 ${ }^{15}$ ", destaca-se:

\begin{abstract}
A situação que se apresenta em decorrência da pandemia da COVID-19 não encontra precedentes na história mundial do pós-guerra. Segundo a UNESCO, milhões de estudantes estão sem aulas com o fechamento total ou parcial de escolas e universidades em mais de uma centena de países devido à pandemia de coronavírus. No Brasil, as aulas presenciais estão suspensas em todo o território nacional (CNE, 2020).
\end{abstract}

A proposta de parecer, posteriormente homologada pelo Ministro da Educação, ao problematizar os possíveis efeitos de longa duração da suspensão das atividades escolares presenciais por conta da pandemia da COVID-19, apontou a dificuldade para reposição de forma presencial da integralidade das aulas suspensas ao final do período de emergência, com o comprometimento severo também do calendário escolar de 2021 e, eventualmente, também de 2022. Além disso, evidenciou alguns riscos percebidos pelo CNE, dentre eles, retrocessos do processo educacional e da aprendizagem ao deixar os estudantes sem atividades educacionais regulares; os danos estruturais e sociais para estudantes e famílias de baixa renda,

\footnotetext{
${ }^{13}$ O Ministério Público do Estado de Alagoas (MPE/AL) promoveu, por meio da Promotoria de Justiça de Traipu, com apoio do Núcleo de Defesa da Educação (NUDED), ação civil pública com pedido de liminar, em caráter de urgência, em desfavor do Município do Traipu, representado judicialmente pelo prefeito Silvino Bezerra Cavalcante, para que o chefe do Executivo Municipal, faça a devida distribuição da merenda escolar, em forma de kits, entre as famílias dos alunos que, por conta do enfrentamento à pandemia do novo Coronavírus, tiveram as aulas suspensas. O promotor de Justiça, Lucas Mascarenhas, requer que, além da continuidade do fornecimento da alimentação, o prefeito viabilize, de todas as formas, o acesso das famílias ao benefício. Caso seja descumprido o pedido, o gestor punido com pena de multa diária de $\mathrm{R} \$ 10$ mil reais e, em caso de atraso superior a 30 dias, o bloqueio de bens e valores suficientes ao cumprimento da obrigação (MELO, 2020).

14 Informações disponíveis em: <https://www.semesp.org.br/wp-content/uploads/2020/05/Parecer-CNECP 5 2020-1.pdf-HOMOLOGADO.pdf>. Acesso em 23 jun. 2020.

15 Disponível em <http://www.anaceu.org.br/download/legislacao/portarias/Proposta-de-Parecer-sobreReorganizacao-dos-Calendarios-Escolares.pdf>, acesso em 15 jun. 2020.
} 
como ausência de merenda, estresse familiar e aumento da violência doméstica; e abandono e aumento da evasão escolar (CNE, 2020).

O documento considera que "tal situação leva a um desafio significativo para todas as instituições ou redes de ensino de educação básica e ensino superior do Brasil, em particular quanto à forma como o calendário escolar deverá ser reorganizado” (CNE, 2020).

Por outro lado, a proposta destacou questões a serem enfrentadas para a reorganização dos calendários escolares, a saber: como garantir padrões básicos de qualidade para evitar o crescimento da desigualdade educacional no Brasil? Como garantir o atendimento dos objetivos de aprendizagens previstos na Base Nacional Comum Curricular (BNCC) e nos currículos escolares ao longo deste ano letivo? Como garantir padrões de qualidade essenciais a todos os estudantes submetidos a regimes especiais de ensino que compreendam atividades não presenciais mediadas ou não por tecnologia de informação e comunicação? Como mobilizar professores e dirigentes dentro das escolas para o ordenamento de atividades pedagógicas remotas? (CNE, 2020).

Por certo são temas que exigem amplo debate incluindo representantes de todos os envolvidos. A questão que se coloca como central neste artigo diz respeito à nossa capacidade, ou não, de construirmos consensos mínimos acerca desses temas. Isso porque o parecer do CNE contém orientações e sugestões para todas as etapas de ensino, da educação infantil à superior e foi elaborado com a colaboração do Ministério da Educação (MEC). Ele tem por objetivo orientar estados, municípios e escolas sobre as práticas que devem ser adotadas durante a pandemia, além de propor normas nacionais gerais, enquanto a reorganização dos calendários é de responsabilidade dos sistemas de ensino, tratando-se de questões que exigem amplo debate.

Ao destacar a responsabilidade de cada sistema de ensino em relação à normatização, o parecer manteve espaço aberto para a adoção de soluções específicas, considerando as realidades próprias dos diferentes entes da federação. Logo, foi interpretada como uma orientação, ou seja, uma sugestão ampla que deverá articulada com “os demais dispositivos legais e normativos relacionados a este tema" (CNE, 2020). O documento contempla diretrizes macro, oportunizando negociações e tomadas de decisão sobre as melhores formas de lidar com os problemas em contextos específicos. 
No parecer, três questões polêmicas foram abordadas, a saber: forma de integralização da carga horária mínima prevista na legislação pertinente ${ }^{16}$; a possibilidade ou não de realização de atividades pedagógicas não presenciais para efeito de cumprimento da carga horária, minimizando a realização de reposição presencial; e a definição dos destinatários das atividades pedagógicas não presenciais.

O cumprimento da carga horária mínima prevista na legislação, de acordo com a proposta de parecer aprovada pelo Conselho Nacional de Educação, poderá ser feita:

[...] por meio das seguintes alternativas, de forma individual ou conjunta: 1 . reposição da carga horária de forma presencial ao final do período de emergência; e 2. cômputo da carga horária de atividades pedagógicas não presenciais realizadas durante o período de emergência coordenado com o calendário escolar de aulas presenciais, após o fim do período de fechamento das escolas (CNE, 2020, n.p.).

Por outro lado, admitiu-se a possibilidade de realização de atividades pedagógicas não presenciais para fins de cumprimento de carga horária mínima exigida por lei, e para minimizar a necessidade de realização de reposição presencial o sistema de ensino,

Por atividades pedagógicas não presenciais entende-se o conjunto de atividades realizadas com mediação tecnológica ou não a fim de garantir atendimento escolar essencial durante o período de impossibilidade de atividades escolares presenciais na unidade educacional da educação básica da educação básica ou de ensino superior (CNE, 2020, n.p.).

Em relação aos destinatários das atividades pedagógicas não presenciais, destacamos:

As atividades pedagógicas não presenciais aplicam-se aos alunos de todos os níveis, etapas e modalidades educacionais, portanto, extensivo àqueles submetidos a regimes especiais de ensino, entre os quais, os que apresentam altas habilidades/superdotação, deficiência e Transtorno do Espectro Autista, atendidos pela modalidade de Educação Especial (CNE, 2020, n.p.).

Ao afirmar que as atividades pedagógicas não presenciais aplicam-se aos alunos de todos os níveis de ensino, etapas e modalidades educacionais, inclusive os atendidos pela Educação Especial, o Conselho Nacional de Educação considera ter adotado uma postura inclusiva, o que pode ser colocado sob discussão diante da percepção de que nem todos os estudantes, no Brasil, têm acesso à internet ${ }^{17}$. Pode ser problematizada, ainda, a ressalva no

\footnotetext{
16 [...] por meio das seguintes alternativas, de forma individual ou conjunta: 1 . reposição da carga horária de forma presencial ao final do período de emergência; e 2. cômputo da carga horária de atividades pedagógicas não presenciais realizadas durante o período de emergência coordenado com o calendário escolar de aulas presenciais, após o fim do período de fechamento das escolas (CNE, 2020, n.p.).

${ }^{17}$ Em 19 de maio de 2020 o Fundo das Nações Unidas para a Infância (Unicef) divulgou que no Brasil não existe internet na casa de 4,8 milhões de estudantes de 9 a 17 anos. E que, com as atividades e aulas on-line, $17 \%$ dos
} 
sentido de que "o uso de meios digitais por parte das crianças deve observar regulamentação própria da classificação indicativa definida pela justiça brasileira e leis correlatas" (CNE, 2020, n.p.). Curiosa advertência demonstrando preocupação com "o que acessar", a despeito das evidentes dificuldades relativas ao "como acessar" os conteúdos disponibilizados on-line.

Considerando os objetivos do parecer, os destinatários e a ressalva, admitiu-se, em tese, o aproveitamento das atividades pedagógicas não presenciais para todos os alunos, ficando sob a responsabilidade dos respectivos sistemas de ensino a normatização específica, especialmente em relação ao aproveitamento da carga horária atribuída para as referidas atividades para fins do cômputo da carga horária mínima prevista na legislação.

A despeito de toda essa produção normativa/diretiva, percebe-se que cada um dos pontos ventilados acima permanece sendo polêmico, e vem dando margem a diversificadas interpretações por parte dos diferentes atores envolvidos, justificando o ajuizamento de ações judiciais de toda sorte. Nessa linha de pensamento, já se pode antever um panorama bastante preocupante em relação à multiplicação de conflitos de interesse. Sobretudo aqueles decorrentes do inadimplemento de obrigações contratuais ou, antes, da tentativa de buscar, pela via judicial, a revisão de contratos de diferentes espécies. Por exemplo, ações destinadas a obter desconto nas mensalidades; para reaver valores pagos durante o período de isolamento diante da alegação de que os serviços não foram integralmente prestados; ou para impor uma determinada forma de prestação dos serviços educacionais (aulas presenciais ou à distância; com ou sem avaliações de desempenho), dentre outros.

Nesse panorama, a adoção maciça de formas inovadoras para lidar com esses conflitos, alternativas ou complementares ao Poder Judiciário, parece ser mais necessária do que nunca e precisa ser considerada. Independente do nome técnico que se lhes atribua, estamos nos referindo à habilidade de dialogar, fazer concessões, colocar-se no lugar do outro e construir soluções dialogadas para atender os interesses de ambas as partes.

Do ponto de vista jurídico, duas das razões que nos levam a fazer essa afirmação são a percepção de que o resultado de uma ação pode ser igualmente incerto, ao lado do princípio de

estudantes matriculados em escolas brasileiras não conseguem acompanhar o conteúdo programático de modo satisfatório. Informações $\quad$ disponíveis em $<$ https://www.em.com.br/app/noticia/educacao/2020/05/19/internas_educacao,1148767/internet-nao-existe-nacasa-de-4-8-milhoes-de-estudantes-no-brasil.shtml>. Acesso em 22 jun. 2020. 
que "o acordo faz lei entre as partes". Quando as partes chegam a um entendimento que pode ser expressado por meio de um documento escrito - um contrato; um termo de acordo/transação; um termo de entendimento em mediação etc - isso significa que a dúvida anteriormente existente está sendo substituída por uma certeza, qual seja, aquela que se expressa nas cláusulas do acordo celebrado, fruto de uma manifestação de vontade dos envolvidos. Isto é: a melhor saída em um cenário de incertezas como este descrito nas linhas acima é a busca de consensos, dentro de contextos específicos.

\section{REFLEXÕES SOBRE A BUSCA DE SOLUÇÕES CONSENSUAIS PARA OS CONFLITOS ESCOLARES}

Notícias levantadas nos sítios eletrônicos de diversificados veículos de imprensa dão o tom do grau de judicialização de conflitos já existente no cenário educacional, devido aos desdobramentos da COVID-19: "Pais pedem que Tribunal de Justiça cancele aulas a distância no Estado" (Folha Vitória, 2020); "Juiz determina que mensalidades de escolas particulares tenham desconto de $20 \%$ no período de suspensão das aulas presenciais decorrente da pandemia da covid-19" (TJAM, 2020); "TJ-RN derruba liminar que suspendia pagamento de mensalidades de aluno da universidade durante pandemia" (Valor Econômico, 2020); "Quarentena: Justiça reduz mensalidades do Santo Agostinho em 30\%” (Veja Rio, 2020) ${ }^{18}$.

Considerando as diferentes realidades que envolvem escolas privadas no Brasil (objeto de nosso interesse, neste artigo) é possível perceber um "caldo" propício ao dissenso entre famílias e escolas em relação aos diferentes aspectos relacionados à educação escolar nesse período de medidas excepcionais de isolamento.

[...] há uma progressiva escalada, em relações conflituosas, resultante de um círculo vicioso de ação e reação. Cada reação torna-se mais severa do que a ação que a precedeu e cria uma nova questão ou ponto de disputa. Esse modelo, denominado de espirais do conflito, sugere que com esse crescimento (ou escalada) do conflito, as suas causas originárias progressivamente tornam-se secundárias a partir do momento

\footnotetext{
${ }^{18}$ Sobre o tema da judicialização da educação, conferir CURY, C. R. J.; FERREIRA, L. A.M. Judicialização da Educação. Revista CEJ, Brasília, Ano XIII, n. 45, P. 32-45; abr/jun, 2009.
} 
em que os envolvidos mostram-se mais preocupados em responder a uma ação que imediatamente antecedeu sua reação (AZEVEDO, 2012, p. 32).

Quando famílias e escolas não se entendem sobre quais são as medidas mais adequadas para a educação escolar nesse período excepcional, bem como sobre os possíveis efeitos das atividades pedagógicas/escolares não presenciais, a tendência de entregar ao Poder Judiciário o poder decisório diante do dissenso torna ainda mais desafiador o diálogo dos envolvidos. A opção pelo processo judicial se torna cada vez mais comum como primeira tentativa, demonstrando o fracasso das partes em construir espaços de consenso para lidar com esses conflitos.

\footnotetext{
Quando a ação é ajuizada, o Estado, na figura do Judiciário, é provocado a intervir no conflito social substituindo a vontade dos particulares para, imparcialmente, buscar a pacificação do conflito que os envolve, com justiça (GRINOVER, 2002, p. 131). Nesse sentido, os sentimentos individuais de justiça são de pouca importância, pois estando o conflito nas mãos do Juiz, que incorpora o Estado, ele se torna "lide" e como tal deve ser composta, resolvida - o que necessariamente não implica em sua administração (DUARTE, 2008). O conflito, ao ser apropriado pelo campo jurídico brasileiro, levando em conta nossa tradição jurídica brasileira, hermética e reducionista, passa a existir a partir de categorias jurídicas que se cerram em relação à sociedade. E como a lide para ser resolvida precisa do processo judicial, este é então saudado como o instrumento para a pacificação. Por si só esta constatação já problematiza a relação entre o tribunal e a sociedade. (DUARTE; ALMEIDA, 2014, p. 23 e 24$)$.
}

Em uma perspectiva instrumental e pragmática, a judicialização dos conflitos escolares, na proporção que se vislumbra para o período de pandemia e pós-pandemia, tem potencial para impactar exponencialmente no funcionamento dos Tribunais, estes já colapsados por milhões de ações judiciais. Não é à toa que CNJ vem trabalhando, há anos (CNJ, 2010) com uma política judiciária de tratamento adequado para os conflitos de interesse que se operacionaliza, mais especificamente, pela implantação da mediação e da conciliação, seja em espaços judiciários ou extrajudiciais.

Ao fazê-lo, no plano discursivo (FILPO, 2016), buscar atender tanto objetivos qualitativos (pertinentes a uma percepção positiva, ligada às qualidades de métodos consensuais de solução de conflitos, como a mediação e a conciliação, quando comparados ao processo judicial) quanto quantitativos (as soluções consensuais são operadas por outros atores que não os magistrados, descentralizando a atividade de solução de conflitos, e prometem ser mais rápidas e econômicas do que a solução convencional, judiciária). 
Ainda no aspecto qualitativo, o uso da mediação (para citar um método consensual com expressa previsão legal, na Lei 13.140/2025) busca despertar o senso de responsabilidade, de respeito pelo outro e de gosto pela decisão, como desenvolvido por Leroy (2012):

Não tememos abordar a verdadeira natureza da questão da sociedade (...); uma questão que é política ou, mais exatamente, cidadã. A mediação é, primeiramente, uma escola de cidadania com senso de responsabilidade, de conhecimentos de competências, de respeito pelo outro e de gosto pela decisão (LEROY, 2012, p. 319).

A mediação é uma prática humana que se manifesta em várias culturas, em múltiplos contextos (segundo COSTA, 2002), de modo que não podemos falar especificamente de uma única forma de "mediar" (cf. MEIRELLES e MIRANDA NETTO, 2014). Neste texto, em que trabalhamos com a perspectiva da existência de um panorama propício ao dissenso entre famílias e escolas em relação aos diferentes aspectos relacionados à educação escolar nesse período de medidas excepcionais, nossa abordagem está centrada, inicialmente, na pessoa que exerce o papel de cuidar de desavenças, ouvir, atuar em conflitos, que em geral visualizamos na figura de um mediador.

Nessa perspectiva, estamos tratando do sujeito que assume um papel relevante entre pessoas que estão com dificuldade de estabelecer um diálogo, uma comunicação positiva. A partir da intervenção desse terceiro, o mediador, se pretende a construção de uma ponte de comunicação. Noutras palavras: um mediador de conflitos, cuja função é facilitar, permitir, reestabelecer as condições de comunicação dos dois polos, família e escola, para que possam cuidar da questão controvertida. A mediação seria, então, um método de autocomposição indireta, ou assistida, onde há um terceiro imparcial intervindo no conflito (AZEVEDO, 2016), de modo a facilitar a comunicação entre as partes. Neste contexto, a posição do mediador se dirige ao reestabelecimento de uma comunicação antes inviável e, por intermédio de sua atuação, equipara as condições de conversa.

O mediador não é um juiz que escolhe um dos lados, nem é um arbitro que determina o pagamento de perdas e danos de um contra o outro, mas um intermediário que tenta reestabelecer a comunicação entre dois para eventualmente reconciliá-los. $\mathrm{O}$ mediador não tem poderes para forçar um acordo nem impor uma solução aos protagonistas. O pré-requisito essencial da mediação é que a resolução do conflito seja obra dos próprios protagonistas. A mediação visa permitir aos adversários que tomem posse de "seu" conflito para que se possam cooperar no sentido de enfrentá-lo, dominá-lo e resolvê-lo eles mesmos. O mediador é um "facilitador", facilitando a comunicação entre os adversários para que expressem seus próprios pontos de vista, ouçam um ao outro, compreendam um ao outro e cheguem a um entendimento (MULLER, 2006, p. 58). 
Esse método tem por proposta interromper os mecanismos de desigualdade de poder (de armas, estruturas, papéis sociais) na medida em que os participantes são tratados pelo mediador como sujeitos de voz igualmente relevante. Ela pode ocorrer até mesmo no contexto das mesas de negociação, propostas na Lei 8.64/2020, do Rio de Janeiro, com representação paritária dos setores interessados (pais, estudantes, professores, representantes da escola etc).

Por sinal, a mediação escolar tem se revelado um tema instigante e atual para juristas, educadores e outros profissionais ligados à Educação. No artigo "Conflitos escolares, espiral do conflito e (por que não?) a mediação?” Filpo (2015) apresentou resultados parciais de pesquisa etnográfica, de caráter exploratório, realizada na cidade de Petrópolis, Rio de Janeiro, tendo como objeto conflitos surgidos em escolas daquele e município e os mecanismos judiciais e extrajudiciais acionados para administrá-los. No artigo "Educar para a mediação: condição para o Êxito da Política Nacional de Tratamento Adequado dos Conflitos de Interesse" Almeida e Filpo (2018) descreveram experiência empírica de emprego da mediação para o tratamento de conflitos escolares e refletiram sobre o potencial de uma educação para a mediação relacionada à Política Nacional de Tratamento Adequado dos conflitos de interesse (CNJ, 2010). De forma sintética, essas pesquisas apontam que existe um espaço a ser ocupado pela mediação no tratamento de conflitos escolares, considerando os aspectos qualitativos e quantitativos envolvidos.

Considerando que "a situação que se apresenta em decorrência da pandemia da COVID19 não encontra precedentes na história mundial do pós-guerra" (CNE, 2020, n.p.) pensar na mediação como meio adequado para a solução de conflitos na relação família /escola após a decretação das medidas de isolamento e a suspensão das aulas no Brasil é uma alternativa que pode se revelar, até mesmo, menos desgastante para as partes envolvidas, especialmente após um período muito difícil na vida de todas as pessoas.

\section{AVERSÃO AO CONSENSO (?) E SENSIBILIDADES JURÍDICAS}

A despeito das apontadas qualidades dos métodos consensuais de solução conflitos e do próprio Poder Judiciário apostar em uma política judiciária destinada a absorvê-los, inclusive 
dentro dos Tribunais, não é regra que as partes envolvidas em um conflito, no Brasil, concordem em abrir espaço para oportunizar o consenso. No caso dos conflitos surgidos na esteira da pandemia isso parece bastante claro e também curioso. Se, a despeito de todo o esforço normativo explicitado linhas acima, ainda há dúvidas sobre o comportamento das instituições e das famílias/estudantes nesse contexto, essas lacunas poderiam ser preenchidas, de forma proveitosa, por soluções consensuais. Nossa prática evidencia, contudo, uma resistência à sua assimilação. O que poderia explicar essa dificuldade? Seria a aversão ao consenso uma característica de nossa tradição jurídica?

Trabalhos produzidos a partir de uma perspectiva interdisciplinar vêm apontando a predominância, no Brasil, de uma cultura jurídica e correspondente sistema de administração de conflitos que tem grande dificuldade em acolher formas mais participativas, uma vez que umbilicalmente atrelado à autoridade - seja a autoridade de quem legisla, seja a de quem julga. A estrutura de contraditório estabelecida em nosso sistema processual consolida moralidades e visões sobre formas de administração de conflitos que não podem ser desconsideradas nessa tentativa de compreender a nossa aversão ao consenso (cf. Kant de Lima, 2011), e que parecem apostar nas figuras de autoridade como as únicas capazes de solucionar conflitos de interesse.

É importante deixar claro que não estamos tratando aqui do princípio do contraditório, de grande importância nos processos judiciais, que implica em assegurar às partes iguais condições de influenciarem de forma eficaz no convencimento do julgador (cf. GRECO, 2015). Duarte e Iorio Filho (2015, p. 27), trabalham uma distinção importante entre princípio e lógica do contraditório, ressaltando que, no processo judicial brasileiro, tem-se, de um lado, a pretensão do “dever-ser", que valora positivamente o princípio do contraditório, a partir de seu aspecto idealizado, como garantidor das partes à igualdade de oportunidades no trâmite do processo; e, de outro lado, a possibilidade do "ser", caracterizada não pelo princípio, mas sim pela lógica do contraditório, que funciona tal qual um "repente nordestino", não permite a construção de sentidos compartilhados e "não opera consensos ou verdades consensualizadas". Em suas palavras (DUARTE e IORIO FILHO, 2015):

Se o princípio do contraditório, tal como tratado pela doutrina e previsto em textos normativos, diz respeito a um "dever ser" no âmbito do processo, a lógica do contraditório é categoria do "ser", pois viabiliza uma compreensão da realidade do mundo jurídico, descrevendo o seu funcionamento no plano discursivo. Desta forma, esta lógica é verificada na empiria e permite explicitar sentidos e práticas que também caracterizam a cultura jurídica brasileira [...] pela lógica do contraditório, as práticas jurídicas discursivas apresentam-se como verdadeiras disputas de "teses ou 
entendimentos ou posicionamentos ou correntes" que só se encerrarão por um ato de vontade da autoridade competente (expresso na decisão judicial), já que a controvérsia tende ao infinito e não há espaço para a construção do consenso (DUARTE e IORIO FILHO, 2015, pp. 27 e 30)

Em outro contexto, Lupetti Baptista (2008) teve oportunidade de discutir a lógica do contraditório como obstáculo à construção de consensos e diálogos no processo judicial brasileiro. Naquela ocasião, estudando os rituais orais do processo e os espaços de fala das partes no curso de uma ação judicial, ela verificou, mediante abordagem empírica, que o contraditório é um obstáculo significativo na construção das formas consensuais de administração de conflitos, notadamente porque provoca nas partes o dever de litigar e, por conseguinte, o dever de discordar. O qual, por sua vez, resulta em incapacidade de construir pontes e diálogos.

Materializado no dever das partes de se contradizerem até o infinito, a lógica do contraditório constrói um mecanismo que transfere para a autoridade e retira das partes a possibilidade de eleger uma forma consensual de solução do conflito. É isso que justifica a referência ao "repente", uma arte brasileira, especialmente forte na região nordeste do país, baseada no canto alternado com a criação de versos de forma, em geral, improvisada. O canto de um sucede o do outro, numa espécie de resposta, configurando uma disputa entre os repentistas.

Amorim (2006, pp. 107-133), ao relatar sua experiência de pesquisa empírica em Juizados Especiais Cíveis e Federais do Rio de Janeiro, também distingue lógica e princípio do contraditório, ressaltando que tal lógica se define pela "supressão da possibilidade de os participantes alcançarem concordância, sejam eles partes do conflito, operadores jurídicos ou doutrinadores, o que sugere ausência de consenso interno ao saber produzido no próprio campo e, no limite, falta de consenso externo, manifesto na distribuição desigual da justiça entre os jurisdicionados pelas mesmas leis que lhes são aplicadas e pelos mesmos tribunais que lhes ministram a prestação jurisdicional” (AMORIM, 2006, pp. 107-133).

Todas essas percepções estão, de certa forma, condensadas e têm o seu sentido revelado com acuidade no texto em que Kant de Lima (2011) explora as "Sensibilidades Jurídicas de Saber e Poder: bases culturais de alguns aspectos do Direito Brasileiro em uma Perspectiva Comparada", quando se propõe a discutir resultados de pesquisas por ele realizadas, com olhar 
antropológico, referentes à compreensão e à aplicação do conceito de sensibilidade jurídica a diferentes contextos jurídicos ocidentais.

A relevância da sua pesquisa é explicada pelo próprio autor quando afirma estar convencido, "seja pelos dados construídos etnograficamente, seja pela observação dos rituais judiciários e policiais, seja na observação e na interação com as práticas pedagógicas inculcadas nos profissionais do direito por sua educação jurídica, formal e informal”, que é possível e relevante distinguir entre dois modelos judiciários, a saber: aqueles que buscam o consenso daqueles outros que se fundamentam no dissenso. A cada um desses modelos o autor atribui uma sensibilidade jurídica (maneira de perceber, lidar ou enxergar o fenômeno jurídico, por assim dizer) distinta que tem implicações na forma como as pessoas, inclusive os profissionais do Direito, encaram e lidam com os conflitos.

No primeiro modelo, tal como se espera ocorrer no ambiente de práticas consensualizadas, há espaço para promover o protagonismo - ou por que não dizer o empoderamento das partes - para que estas cheguem juntas à solução que melhor lhes interesse. Para que isso ocorra, é necessário que efetivamente acreditem ser este o melhor caminho a seguir. Mas essa pretensão faz pouco sentido quando fatores culturais apontam a autoridade judiciária como a única capaz de dar ponto final a uma disputa.

Contudo, segundo o mesmo autor (2011, p. 28), em ambientes impregnados pela lógica do contraditório, sejam eles judiciários ou não, observa-se a "promoção de um dissenso infinito, o qual só se interrompe através de uma autoridade externa às partes, que lhe dá fim e declara uma tese vencedora e a outra, vencida". Essa lógica, ainda segundo o mesmo autor, seria própria dos modelos judiciários calcados no dissenso, que se distinguem daqueles baseados no consenso. Os primeiros correspondentes a sociedades formadas por iguais, e os últimos correspondentes a sociedades hierarquizadas, que o autor identifica como piramidais - isto é, em que apenas poucos têm condições de ascender ao topo da pirâmide, sociedades, portanto, marcadas pela desigualdade.

É nesse sentido que a lógica do contraditório, por propor uma relação necessariamente competitiva ou conflituosa, acaba sendo um empecilho à construção de consensos e diálogos no processo (ou mesmo fora dele, por conformar uma certa percepção sobre a forma como um conflito deve ser resolvido) e dificulta possibilidades cooperativas e uma participação ativa e 
conjunta das partes na administração dos conflitos. Como perceberam Duarte e Iorio Filho (2015, p. 36) a "lógica do consenso" estrutura procedimentos discursivos decisórios/interpretativos que prestigiam e voltam-se à formação de acordos/consensos, permitindo que se esteja diante "da autoridade do argumento". Em contraposição, a "lógica do contraditório" opera pela (e a partir) da divergência, valendo-se da autoridade. Por isso um recurso bastante utilizado pelos juristas em suas manifestações processuais é justamente o chamado "argumento de autoridade", que costuma ser utilizado na pretensão de sobrepor-se até mesmo aos mais razoáveis e lógicos argumentos.

\section{CONCLUSÃO}

No caso da discussão estabelecida neste texto, pareceu bastante clara a dificuldade encontrada pelos envolvidos nos contratos educacionais, tornados conflituosos em função da COVID-19, de entrarem em entendimento sobre as melhores formas de lidar com esses conflitos, lançando mão de ferramentas como a mediação, a conciliação, as mesas de negociação, dentre outros, para encontrar soluções consensuais.

Claro que não é simples lidar com as consequências da pandemia ao inaugurar uma nova ordem em todos os campos de atuação humana, além do que a atividade educacional está sujeita a vasta regulamentação, o que torna o tema bastante complexo. Mas é curioso que as soluções consensuais não sejam buscadas em primeiro lugar, e que a autonomia das pessoas e instituições seja substituída pela manifestação da autoridade, inclusive se antecipando a uma verificação mais detida das especificidades de cada caso.

Diante de um quadro de flagrante insegurança jurídica, sucederam-se inúmeras tentativas de regulamentação, recaindo sobre os mais diferentes aspectos dessa relação entre escolas, estudantes e suas famílias, sem que tais normativas conseguissem apontar caminhos seguros. Tanto que foram e vêm sendo objeto de inúmeras ações judiciais, como demonstrado neste paper - algumas delas, não raro, com resultados contraditórios e igualmente questionáveis. 
Parece bastante clara a nossa dificuldade em absorver formas consensuais de solução de conflitos e isso pode ser explicado (para além das dificuldades inerentes ao tema do Direito à Educação e ao contexto pandêmico), a partir de um olhar antropológico, por uma determinada sensibilidade jurídica que parece repelir o consenso. Não é algo que possa ser modificado tão facilmente, por se tratar de um aspecto cultural.

Mas talvez a pandemia e as mudanças que ela vem impondo possam convencer até mesmo os mais resistentes de que é necessário aperfeiçoar nossos mecanismos de solução de conflitos. Talvez seja preciso dar às soluções consensuais uma oportunidade. Talvez esse seja um caminho viável em busca de maior segurança jurídica. Enquanto isso, permanecemos andando na corda bamba.

\section{REFERÊNCIAS BIBLIOGRÁFICAS}

ALMEIDA, Carlos Alberto Lima de; ALMEIDA, Gabriel G. S. Lima de. Análise do impacto inicial das medidas excepcionais de isolamento em decorrência do novo Coronavírus, COVID 19, na prestação do serviço de educação escolar realizado na educação básica por escolas privadas do Sistema de Ensino do Estado do Rio de Janeiro. Artigo completo apresentado na edição 2020 do Congresso Internacional de Altos Estudos em Direito. Brasil. 2020.

ALMEIDA, Carlos Alberto Lima de; FILPO, Klever Paulo Leal. Educar para a Mediação: condição para o êxito da Política Judiciária Nacional de Tratamento Adequado dos Conflitos de Interesse. Anais Sociology of Law 2018: o Direito entre o Caos e a Reconstrução. Disponível em <http://hdl.handle.net/11690/1106>. Acesso em 24 jun. 2019.

AMORIM, Maria Stella de; KANT DE LIMA, Roberto; MENDES, Regina Lúcia Teixeira (Org.). Ensaios sobre a igualdade jurídica: acesso à justiça criminal e direitos de cidadania no Brasil. Rio de Janeiro: Lumen Juris, 2005, introdução.

AMORIM, Maria Stella de. Juizados Especiais na Região Metropolitana do Rio de Janeiro. Revista da Seção Judiciária do Rio de Janeiro, n. 17, 2006, pp. 107-13.

AZEVEDO, André Gomma de (Org.) Manual de Mediação Judicial. Brasília: Ministério da

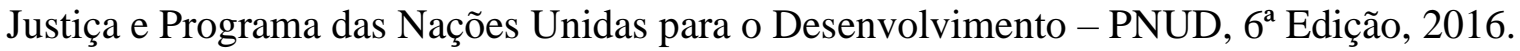

BRASIL. Conselho Nacional de Educação. Proposta de Parecer sobre a Reorganização dos Calendários Escolares e Realização de Atividades Pedagógicas Não Presenciais durante o Período de Pandemia da COVID-19. Disponível em 
<http://portal.mec.gov.br/index.php?option=com_docman\&view=download\&alias=145011pcp005-20\&category_slug=marco-2020-pdf\&Itemid=30192>. Acesso em 20 mai. 2020.

BRASIL. Conselho Nacional de Justiça. Resolução $n^{0}$ 125/2010. Disponível em <http://cnj.jus.br/programas-e-acoes/conciliacao-mediacao/legislacao>. Acesso em 02 mar. 2015.

BRASIL. Constituição da República Federativa do Brasil: promulgada em 5 de outubro de 1988. São Paulo: Saraiva, 2020.

BRASIL. Decreto nr. 8.243/2014 - Institui a Política Nacional de Participação Social - PNPS e o Sistema Nacional de Participação Social - SNPS, e dá outras providências. Disponível em $<$ https://presrepublica.jusbrasil.com.br/legislacao/120466065/decreto-8243-14>. Acesso em 10 mai. 20.

BRASIL. Lei $\mathrm{n}^{\mathrm{o}} 13.105 / 2015$ - Institui o Código de Processo Civil. Disponível em <http://www.planalto.gov.br/ccivil_03/_Ato2015-2018/2015/Lei/L13105.htm>. Acesso em 18 mar. 2015.

BRASIL. Lei $n^{\circ}$ 13.140/2015 - Dispõe sobre a mediação entre particulares como meio de solução de controvérsias e sobre a autocomposição de conflitos no âmbito da administração pública. Disponível em <http://www.planalto.gov.br/ccivil_03/_ato20152018/2015/lei/l13140.htm>. Acesso em 01 mai. 2018.

COSTA, A. A. Métodos de composição de conflitos: mediação, conciliação, arbitragem e adjudicação. In: AZEVEDO, A. G. (org.). Estudos em arbitragem, mediação e negociação. Brasília: Brasília Jurídica, 2002, pp. 161-201.

CURY, C. R. J.; FERREIRA, L. A.M. Judicialização da Educação. Revista CEJ, Brasília, Ano XIII, n. 45, p. 32-45, abr/jun, 2009.

DUARTE, Fernanda; ALMEIDA, Gabriel Guarino de. Práticas judiciárias e mediação de conflitos: uma experiência no Tribunal de Justiça do Rio de Janeiro. In: MENDES, Regina Lucia Teixeira; DANTAS, Fernando Antonio de Carvalho; ROCHA, Leonel Severo (Orgs.). Sociologia, Antropologia e cultura jurídicas - CONPEDI UNINOVE. 1ed.Florianópolis: FUNJAB, 2014, v., pp. 22-50.

DUARTE, Fernanda; IORIO FILHO, Rafael Mario. A lógica do contraditório: ainda somos medievais. In: SIQUEIRA, Gustavo Silveira; WOLKMER, Antonio Carlos; PIERDONÁ, Zélia Luiza (Orgs.). História do direito. Florianópolis: CONPEDI, 2015, pp. 1-23.

FILPO, Klever Paulo Leal. Conflitos Escolares, Espiral do Conflito e (Por que não) a Mediação? Revista de Formas Consensuais de Solução de Conflitos, v.1, n. 1, 2015. DOI: http://dx.doi.org/10.26668/IndexLawJournals/2525-9679/2015.v1i1.401.

FILPO, Klever Paulo Leal. Mediação Judicial: Discursos e Práticas. Mauad X: FAPERJ, 2016.

GRECO, Leonardo. Instituições de Processo Civil. Introdução ao Direito Processual Civil. Rio de Janeiro: Forense, 2015. 
KANT DE LIMA, Roberto. Sensibilidades jurídicas, saber e poder: bases culturais de alguns aspectos do direito brasileiro em uma perspectiva comparada. Anuário Antropológico, v. 2, 2011, pp. 25-51.

LEROY, E. O lugar da juridicidade na mediação. Meritum, Belo Horizonte, v. 7, n. 2, p. 289324, jul./dez. 2012.

LUPETTI BAPTISTA, Bárbara Gomes. Os Rituais Judiciários e o Princípio da Oralidade: construção da verdade no processo civil brasileiro. Porto Alegre: Sergio Antonio Fabris Editor, 2008.

MEIRELLES, Delton Ricardo Soares; MIRANDA NETTO, Fernando Gama de. Reflexões sobre a conciliação e a mediação civil no âmbito judicial e extrajudicial. In: MUNIZ, Joaquim de Paiva et al. (Coord.). Arbitragem e mediação: temas controvertidos. Rio de Janeiro: Forense, 2014.

MESQUITA, Sarah Carolina. Mensalidades Escolares e a COVID-19. Artigo de Opinião publicado na Revista Consultor Jurídico. 21 abr. 20. Disponível em <https://www.conjur.com.br/2020-abr-21/sarah-mesquita-mensalidades-escolares-covid-19>. Acesso em 10 mai. 2020.

MULLER, J. Não-violência na educação. São Paulo: Palas Athenas, 2006.

PEDROSO, Alberto Gentil de Almeida; ZEGER, Arthur. COVID-19, Quarentena e o Contrato Educacional. Artigo de Opinião publicado na Revista Consultor Jurídico. 30 mar. 20. Disponível em: <https://www.conjur.com.br/2020-mar-30/zeger-pedroso-covid-19quarentena-contrato-educacional>. Acesso em 10 mai. 2020.

Data de Submissão: 23/11/2020

Data de Aceite: 07/12/2020 